\title{
A qualitative study exploring genetic counsellors' experiences of counselling children
}

\author{
Fiona Ulph ${ }^{\star, 1}$, James Leong ${ }^{2}$, Cris Glazebrook ${ }^{3}$ and Ellen Townsend ${ }^{4}$
}

The identification of healthy carriers by newborn screening programmes raises questions about how and when the carrier results will be conveyed to child. There is currently a lack of information concerning how best to convey carrier information to children. This is a serious gap in the literature and practice. This study examined genetic counsellors' experiences of counselling children to explore how to support and inform children about their carrier result. Practising members of the United Kingdom (UK) Association of Genetic Nurses and Counsellors took part in semi-structured telephone interviews. Respondents described the communication process and identified barriers and facilitators of communication. Age, illness experience and maturity were variously discussed as facilitators; all of which are integral to psychological theories of children's understanding of illness. Adaptive family communication, school tuition and educational materials were also seen as influencing counselling efficacy. Relevant materials that children could keep were also seen as important to enhance children's autonomy. Yet, such resources were rare, constituting a barrier to communication. Counsellors reported communication was further impeded by maladaptive family communication and resistance from children to engaging in counselling. By exploring the facilitators and barriers inherent in communicating genetic information to children, guidance can be offered to counsellors, researchers and parents. This study indicates that some factors (eg illness experiences) previously identified by psychological theories may act in complex ways within this setting. Importantly, the factors identified as being most influential when communicating with children about genetics are amenable to change through interventions, support and training.

European Journal of Human Genetics (2010) 18, 1090-1094; doi:10.1038/ejhg.2010.86; published online 9 June 2010

Keywords: Genetic counselling; children; newborn screening; carrier; family communication

\section{INTRODUCTION}

Newborn screening for sickle cell and cystic fibrosis identifies around 250 carriers of cystic fibrosis (KW Southern, personal communication) and 8686 carriers of sickle cell in the UK annually. ${ }^{1}$ The benefits of knowing one's carrier status are largely linked to informed reproductive decision-making, as being a carrier infers a one in four risk of children being affected by the disease if both parents are carriers. For the benefits of carrier information to be realized, individuals need to appreciate the difference between affected and carrier states and understand the probability-based reproductive implications of the latter. Carriers will ideally need to be aware of their status before they become sexually active. Yet, no clear guidelines exist about when and how to convey carrier information to children. ${ }^{2}$ Moreover, there is a general lack of research about how children understand genetic illnesses ${ }^{3}$ or testing, ${ }^{4,5}$ how such information should be conveyed to them ${ }^{6}$ and what factors may affect communication efficacy. This is despite the evidence that parents and health professionals can find communication about genetics with children difficult. ${ }^{7,8}$ Clearly, this represents a serious gap both in the literature and in practice as the consequences of inadequate communication about genetic test results to young people will at a minimum result in ill-informed decision-making later in life and may lead to distress for both the individual and the family.

Studies have explored children's psychosocial adaptation to genetic testing, ${ }^{9-12}$ and the feasibility of secondary school genetic testing programmes. ${ }^{13-21}$ Concerns remain, however, about children's ability to understand carrier status results following newborn screening as a recent interview study of parents who had received carrier results for their child following newborn screening reports that school-based learning may be one of the triggers for parents to inform their child. ${ }^{22}$ Yet, pupils evidence difficulty in comprehending genetics even after formal tuition, ${ }^{23-27}$ and it is likely that children who are unaware of their genetic risk and the relevance of the science curriculum are likely to show a similar knowledge profile. It is likely, therefore, that such children would benefit from additional materials to help them assimilate and adapt to their results.

Genetic counsellors are trained to convey genetic information in the simplest form possible and by examining their experiences and views, this research aimed to explore how best to communicate personally relevant genetic information to children.

\section{METHOD}

This cross-sectional, qualitative study used semi-structured interviews to explore genetic counsellors' experience of counselling children. Qualitative methodologies are optimal when minimal research exists, or where the researcher wishes to examine participants' views and experiences. ${ }^{28}$ Semi-structured interviews with open questions permit flexibility and minimize the researcher influence on participants' responses.

\section{Recruitment}

All UK regional genetic centres were contacted to establish the total number of practising genetic counsellors registered with Association of Genetic Nurses and

${ }^{1}$ School of Psychological Sciences, University of Manchester, Manchester, UK; ${ }^{2}$ Ophthalmology Department, Dunedin Hospital, New Zealand; ${ }^{3}$ Division of Psychiatry, University of Nottingham, Nottingham, UK; ${ }^{4}$ School of Psychology, University of Nottingham, Nottingham, UK

*Correspondence: Dr F Ulph, School of Psychological Sciences, University of Manchester, Oxford Road, Manchester M13 9PL, UK. Tel: +44 1612751979 ; Fax: +44 161275 1000; E-mail: fiona.ulph@manchester.ac.uk

Received 18 June 2009; revised 20 April 2010; accepted 21 April 2010; published online 9 June 2010 
Counsellors in the UK. Contacts in each centre were sent the requisite number of study packs to distribute (information sheet, interview request form, consent form and freepost envelopes; total $N=207$ ). Counsellors who returned an interview request form were contacted (by FU and JL) to arrange a mutually convenient time to be interviewed.

\section{Interviews}

To enable a wide geographical coverage, telephone interviews were conducted. The interview schedule was developed by a team of experts, including a genetic counsellor, and guided by previous research. It was piloted with two genetic counsellors and the schedule was adjusted accordingly. Interviewees were first asked to discuss any experiences of counselling children, later they were asked about their views regarding conveying carrier status results to children. Interviews were digitally recorded by a telephone adaptor. Interviews were transcribed verbatim, identifiable information was removed and pseudonyms were assigned.

\section{Analysis}

Data were analysed by Nvivo version 2.0 using thematic analysis. ${ }^{29,30}$ Thematic analysis is method of analysing qualitative data, which results in a rich, yet accessible account of the data, rather than a theoretic approach. ${ }^{29,30}$ The researcher seeks to make sense of the data and to report patterns inherent within the data collected. ${ }^{30}$ Within this study it was used as a realist method that reported the experiences of participants. Transcripts were reviewed and coded by two researchers (FU and $\mathrm{JL}$ ) with guidance from an experienced qualitative researcher (CG). Themes were coded inductively at a manifest level to develop practice suggestions for health professionals. Coding was conducted systematically and iteratively; transcripts were reviewed against emerging themes. No new themes emerged during the final interviews suggesting saturation was achieved.

Consistency of an independent coder attributing themes to selected excerpts is often used as a method of checking the reliability in qualitative methods. ${ }^{31}$ Codebooks listing and describing the themes were constructed (by FU) under the supervision of an experienced qualitative researcher (CG). Two independent researchers were given the codebooks and interview excerpts selected by the lead analyst (FU) and were asked to code the excerpts using the themes. Percentage agreement on presence of the theme was then calculated.

\section{Ethical approval}

The University of Nottingham Medical School Research Ethics Committee granted approval for this study to be conducted.

\section{RESULTS}

A total of 33 interview request forms were returned. Interviews could not be arranged within the study period for five respondents. One interview was excluded due to poor recording quality, resulting in 27 analysed interviews. Interviews were conducted with counsellors working in 9 of 10 strategic health authorities in England, and in Scotland, Wales and Northern Ireland. Median number of working years was 5 (range 6 months to 20 years). Interviews lasted an average of $45 \mathrm{~min}$. Agreement was $>70 \%$ for all themes - the required level to accept the reliability of themes. ${ }^{29}$ Themes were grouped into communication process, barriers to and facilitators of communication. Interview excerpts are presented to facilitate judgements of trustworthiness.

\section{Processes of communication: facilitating autonomy}

Interviewees recognized the difficulties of balancing the needs of the child and the attendant parent during counselling. Enabling child participation and ownership was central to many interviewees' experiences. This was achieved in many ways. The most overt was by asking parents to leave the room. Although it was felt this enhanced communication, some counsellors were unsure whether this was permissible:

...two separate consultations that would be the ideal, because

I think, from 12 onwards we're, you know, we should be treating them like adults really, but obviously there's this thing of you know Gillick competence and all that, so you have to be jolly careful, don't you. (Jane)

...if I'd insisted on seeing them separately it might have been different, but I'm not sure, well I don't think you can - not with children anyway. (Vicky)

Suitability of this strategy was linked to the child's age, with most individual counselling sessions occurring with adolescents. Another strategy was to address the child directly or give them control of the communication 'If I am talking to a child I might say - 'Is it alright if I ask your mum about that?' I think it's important that a child feels in the driving seat' (Alexa). Provision of information materials also conferred ownership to children.

\section{Process of communication: facilitating communication}

Interviewees facilitated communication by encouraging children to draw or to play with materials 'If you give them a piece of paper and a pen and $[\ldots]$ you make it a sort of game, they will join in and they'll be far easier to talk to' (Emma). By focusing drawings or play on unrelated topics, the child and counsellor could interact in a less threatening way before discussing genetics. Drawings also helped to examine the child's understanding:

...get them to draw pictures of how they're, how they see the situations...I think with children you can gauge a lot from things like that. [...] I think it's quite hard to get them to understand and to also gauge their understanding of conditions... (Vicky)

\section{Barriers to effective counselling: the taciturn child}

The interviewees reported that some older children were reluctant to engage in counselling:

... it is often very difficult because often, as you know, children are not very forthcoming. And teenagers particularly I suppose in my experience, teenage boys, tend to have a major period in their lives when they are pretty monosyllabic so it can be difficult if not impossible sometimes to check out [their understanding]. (Tara)

Although adolescents may be uncommunicative for many reasons including anxiety or an inability to understand, this often resulted in the counselling being postponed.

Some interviewees tried using direct question to encourage children to talk, but this was not always successful ' [it] only required a kind of yes or no answer they were very reluctant even to do that'. (Vicky)

\section{Barriers to effective counselling: lack of resources}

Interviewees reported a lack of suitable materials, forcing them to use conference materials, adapt materials or make their own. Many wanted leaflets, whereas others wanted interactive materials such as anatomical models. Counsellors believed such resources would be useful when communicating complex ideas and to provide children with ownership:

... it would be quite nice to having something that's real basic, some real basic diagrammatic stuff, just so they feel that it wasn't something for Mum and Dad. (Emma)

\section{Barriers to effective counselling: maladaptive family} communication

Although effective family communication was a facilitator, maladaptive family communication was a hard barrier for counsellors to 
negotiate. Interviewees reported cases where the illness had not been discussed within the family, or that stories had been constructed to try and protect the child - unfortunately, however, this was rarely effective:

I had one girl who was told about the genetic condition in her family on her 16th birthday, because they thought that was a good time. She was 16 and she should know about it. She was really angry and came along to clinic, and had always been told that her mum had had one thing and actually she had something else. You know, I think parents may try to protect the children and not actually tell them what it is. (Nancy)

In one extreme case a counsellor believed the parent had intended to distress the child. This caused many problems not least because the counsellor had to counteract the misinformation given by a trusted adult.

Interviewees also cited the 'messenger's' lack of understanding as a reason, often because the 'messenger' received genetic counselling many years ago:

I have come across cases where individuals have come forward for testing and they have had wrong information passed to them about level of risk and carrier status and it's been passed on by the family. (Emily)

Other family communication difficulties identified by counsellors included parents not knowing when they should tell their child the information '[the parents] don't feel their children are ready for that information and they don't pass it on' (Barbara). This was a case where the child was a teenage daughter whose father had an adult onset autosomal dominant condition.

Facilitators of understanding: adaptive family communication Effective family communication facilitated communication and provide children with models of how to communicate themselves, as reflected by Jane's comment 'It's all about how families share information isn't it, and the children are just the product of that and will behave accordingly themselves'. Some parents supported the child to enable them to communicate, whereas others were integral in communicating information to their children:

... I didn't want to go down areas they hadn't discussed with him before. I halted and his Mum took the hint and took over and so it was very much in partnership with Mum. It worked very well. (Barbara)

\section{Facilitators of understanding: illness experience}

Many interviewees reported an impact of illness experience on counselling children '...they don't have any experience of the actual condition so it's, you know, quite hard to probably even visualise what we were really talking about'. (Vicky) Experience of the illness also gave children a broader understanding:

...the ones that have been brought up very close to the condition [...] they really are usually very well informed, both about the facts but also about the implications.... (Susan)

Another facet of illness experience was described by Sarah 'A child that sees maybe a brother or a sister who's really badly affected might be a very frightened child'. Thus, health professionals and researchers should be aware that illness experience may not always benefit a child.

\section{Facilitators of understanding: age/maturity}

Interviewees reported maturity had an important, yet complex role in understanding. Initially many said the child's age was influential, but their explanations made it clear that age was being used as a proxy for maturity. Indeed, it was recognized that age was unreliable: '... you could see a 12 year old one day and they understand nothing, and you can see a 12 year old the next day and they're really switched on'. (Nancy)

\section{Facilitators of understanding: science education}

Many counsellors discussed the important role science education had in the formation of children's knowledge. This was supported by some interviewees: ' ... it is part of the GCSE biology course (GCSE (General Certificate of Secondary Education) are the courses studied in the fourth and fifth year of secondary school in England (aged 14-16 years)), my daughter was taught it, so maybe there could be some sort of general PSE [Personal and Social Education] talk that they have you know..., (Helen) but she described possible problems: '... if the children learn about it at school and then go back and the parents say 'Oh yes you were tested and you are a carrier' - I think the children might wonder why it hadn't been discussed with them before'. Some interviewees stressed the importance of covering the social side of genetics:

.... a straight forward science class deals with the nuts and bolts of it and the sort of how it works and what the consequences might be, they then don't deal with what the psychological issues are for people which are probably much greater than knowing that that's a dominant condition. (Nicola)

Some explained how this differentiated children from adults, as sometimes the child was more capable of understanding the counselling than the adult:

I am thinking about children aged 15, 16 perhaps who are doing GCSE biology I certainly have had much more scientific conversation with them than perhaps their parents, they really do know about it. (Diana)

This has important implications, as newborn screening involves parents in understanding and conveying carrier result to their children.

\section{DISCUSSION}

By exploring genetic counsellors' experiences of counselling children, this study has elucidated the communication processes, and identified potentially modifiable barriers and facilitators that may improve communication with children about personally relevant genetic information. These are important findings given the current paucity of information available to counsellors specifically in relation to their work with children. Indeed, interviewees often requested information and feedback from the interviewers on current practice regarding counselling children, which suggests that our results provide an important overview and addition to knowledge and practice in this field.

Many counsellors reported behaviours recognized as best practice in health communication. For example, offering to see adolescents alone. $^{32}$ Although understandably many questioned whether this was appropriate with younger clients, children could be empowered to be autonomous by directing communication to them. This may be most effective if coupled with starting by talking about nonthreatening topics, or to communicate through play, as has been advised in genetic counselling. ${ }^{33}$ Specifically, activities, such as drawing, which have been used extensively in the disciplines of education, psychology and psychiatry to make inferences about understanding 
and psychological state, ${ }^{34}$ may provide the counsellor with insight into the child's current understanding, a crucial part of genetic counselling that is challenging if the client is a child. ${ }^{35}$ This can provide the building blocks upon which to build further genetic knowledge as proposed by Vygotsky's learning theory of proximal development. ${ }^{36}$

Although family communication processes of genetic risk are increasingly well documented, children are rarely included in such research. ${ }^{2}$ Yet, family communication supplies children with the blueprint for reacting to situations and stressors. ${ }^{37}$ Counsellors reported a tendency for some families to try and shield children from information, a behaviour identified in previous studies, ${ }^{38,39}$ which often causes distress. A retrospective study of people's experiences of carrier testing conducted before they were 18 reported that parents struggle to inform and support their children. ${ }^{40}$ Other research has suggested that parents' information provision to children may be inadequate, ${ }^{41}$ reflecting the challenging nature of these discussions for some families and underlining the need for studies into how families communicate with, and support, children.

Family communication has been facilitated by providing information materials designed for children, by increasing adults' understanding of illness and providing parents and child with a common language with which to discuss illness. ${ }^{42}$ Counsellors found that materials enabled the child to communicate and facilitated autonomy. Indeed, supplying information materials to clients following genetic counselling is advocated as best practice, ${ }^{6}$ further highlighting the benefits making information materials, based on developmental research, easily accessible to health professionals and parents.

The taciturn child represented a major challenge that effectively halted counselling sessions. Negative responses by adolescents to genetic counselling have been attributed to anxiety and lack of understanding, ${ }^{43}$ and it has been proposed that difficulties in confronting or verbalizing concerns can impede genetic counselling for both adults and children. ${ }^{33}$ Furthermore, young people have reported high levels of mistrust and misperceptions about genetic counselling. ${ }^{4}$ One suggested strategy - to guess how the child feels ${ }^{33}$ - was used by some counsellors with limited success. Importantly, this technique may contradict client-led counselling. ${ }^{45}$ Rather it may be better to acknowledge that silence or limited communication may be a protective response to medical diagnoses ${ }^{46}$ and, despite counsellors' efforts, children may find it hard to distinguish between genetic counselling and other medical consultations. Indeed, it has been proposed that 'Denial is perhaps the most straightforward [strategy to cope with genetic threat] - to try to ignore the issue, refuse to discuss it and to keep well away from geneticists' (Richards, ${ }^{47}$ pp. 266-267). Thus, reluctance may indicate that children appreciate the seriousness of the situation, but feel overwhelmed and therefore try to distance themselves from it.

Genetic education within schools was something which all genetic counsellors perceived positively and it has been argued that school education may be the optimum strategy for increasing knowledge in adolescents who live in a society where the population's knowledge of genetics is poor. ${ }^{48}$ Yet, one should be cognisant that children may be aware of genetics and able to use genetic terminology with little understanding of the concepts. ${ }^{23-27}$ The timing of disclosure of genetic risk in relation to formal education on genetic inheritance was also an issue. One counsellor highlighted the possible negative consequences for the child of disclosure being triggered by teaching on the topic at school, supporting the need to ensure that families are fully supported to inform their children in a timely manner.

The influence of the other facilitators (eg maturity and illness experience) is well documented in the literature. Some argue that a child's maturity is the crucial determinant of whether they should have genetic tests performed. ${ }^{49}$ Counsellors in this study largely used age only as a proxy for maturity, which suggests that research on children's understanding of illness should re-focus from examining age alone, to examining age as a marker of maturity. Especially as Borry et al ${ }^{50}$ have shown that clinicians have concerns about judging whether people of particular ages are mature enough to make autonomous decisions about predictive or presymptomatic tests. Previous research also shows that illness experiences affect whether individuals wish to have genetic tests, ${ }^{51}$ how they understand test results ${ }^{52}$ and make reproductive decisions. ${ }^{53}$ Previous experience with an illness may function as a barrier for adults, whereby memories of a person affected by illness become more influential than medical facts given by health professionals. ${ }^{54}$ However, illness experience has also been previously identified as a facilitator to understanding in psychological theories of children's understanding of illness. ${ }^{55}$ This study suggests, however, that the relationship between these two factors and understanding or adaptation can be complex. For example, there may be negative consequences where a client is older or has more experience of the disease. There is now a need for research that examines the utility of theories of children's understanding of illness in this context, and the acceptability of generalizing findings from studies with adults to children.

A criticism of qualitative research is that it is too subjective and the researchers' beliefs directly contribute to the findings. ${ }^{31}$ The range of views elicited during the interviews suggests that counsellors felt able to discuss the issues pertinent to them, and the broad geographical and experience range further reduces the chance of bias.

In conclusion, genetic counsellors currently use a range of strategies to engage children in counselling, but are unsure about best practice, including when to inform children and how parents could be supported to do this. Concerns were raised that family communication could cause anxiety and misunderstandings and the need for appropriate educational resources to facilitate health professionals' and parents' communication with children about genetics was clearly established. Education, both in terms of school-based education and within the family, was seen as very beneficial. Parents need support to provide their child with information about their carrier status. This basic understanding could serve as framework to help the child assimilate relevant information from the science curriculum and from informal sources as this research suggests that children start forming genetic knowledge before the age at which formal tuition is offered.

\section{CONFLICT OF INTEREST}

The authors declare no conflict of interest.

\section{ACKNOWLEDGEMENTS}

We thank the Economic and Social Research Council (ESRC) who provided funding for this study through a $\mathrm{PhD}$ studentship for the project 'Children's understanding of testing for a genetic illness'. The ESRC played no active role in the research or publication.

1 Streetly A, Latinovic R, Hall K, Henthorn J: Implementation of universal newborn bloodspot screening for sickle cell disease and other clinically significant haemoglobinopathies in England: results for 2005-7. J Clin Pathol 2009; 62: 26-30.

2 Borry P, Goffin T, Nys H, Dierickx K: Attitudes regarding carrier testing in incompetent children: a survey of European clinical geneticists. Eur J Hum Genet 2007; 15: 1211-1217.

3 Sparbel KJL, Driessnack M, Williams JK et al: Experience of teens living in the shadow of Huntington disease. J Genet Couns 2008; 17: 327-335. 
4 Tercyak KP, Peshkin BN, Streisand R, Lerman C: Psychological issues among children of hereditary breast cancer gene (BRCA1/1) testing participants. Psychooncology 2001; 10: 336-346.

5 Kohlmann W, Holter S, Leninger A, Peterson S: Assessment of knowledge in parents and children from families with familial adenomatous polyposis. J Genetic Couns 2006; 15: 2 .

6 European Commission. Science and Society: 25 Recommendations on the Ethical, Legal and Social Implications of Genetic Testing. Brussels: European Commission, 2004.

7 Metcalfe A, Coad J, Plumridge GM, Gill P, Farndon P: Family communication between children and their parents about inherited genetic conditions: a meta-synthesis of the research. Eur J Hum Genet 2008; 16: 1193-1200.

8 van den Nieuwenhoff HWP, Mesters I, Gielen C, de Vries NK: Family communication regarding inherited high cholesterol: why and how do patients disclose genetic risk? Soc Sci Med 2007; 65: 1025-1037.

9 Kai J, Ulph F, Cullinan T, Qureshi N: Communication of carrier status information following universal screening for sickle cell disorders and cystic fibrosis: qualitative study of experience and practice. Health Technol Assess 2009; 13: 1-106.

10 Codori AM, Zawacki KL, Petersen GM et al: Genetic testing for hereditary colorectal cancer in children: long-term psychological effects. Am J Med Genet 2003; 116A: 117-128.

11 Jolly A, Parsons EP, Clarke A: Testing children to identify carriers of balanced chromosomal translocations: a retrospective, qualitative psychosocial study. $J$ Med Genet 1996; 33: 6.018.

12 Michie S, Bobrow M, Marteau TM: Predictive genetic testing in children and adults: a study of emotional impact. J Med Genet 2001; 38: 519-526.

13 Duncan RE, Gilliam L, Savulescu J, Williamson R, Rogers JG, Delatycki MB: 'You're one of us now': young people describe their experiences of predictive genetic testing for Huntington disease (HD) and familial adenomatous polyposis (FAP). Am J Med Genet $C$ Semin Med Genet 2008; 148: 47-55.

14 Barlow-Stewart K, Burnett L, Proos A et al: A genetic screening programme for Tay-Sachs disease and cystic fibrosis for Australian Jewish high school students. J Med Genet 2003; 40: e45.

15 Cobb E, Holloway S, Elton R, Raeburn JA: What do young people think about screening for cystic fibrosis. J Med Genet 1991; 28: 322-324.

16 Harel A, Abuelo D, Kazura A: Adolescents and genetic testing: what do they think about it? J Adolesc Health 2003; 33: 489-494.

17 Gason AA, Aitken MA, Metcalfe SA, Allen KJ, Delatycki MB: Genetic susceptibility screening in schools: attitudes of the school community towards hereditary hemochromatosis. Clin Genet 2005; 67: 166-176.

18 Kaplan F, Clow CL, Scriver CR: Cystic fibrosis carrier screening by DNA analysis: a pilot study of attitudes among participants. Am J Hum Genet 1991; 49: 240-242.

19 Mitchell J, Scriver CR, Clow CL, Kaplan F: What young people think and do when the option for cystic fibrosis carrier testing is available. J Med Genet 1993; 30: 538-542.

20 Burnett L, Proos A, Chester D et al: The Tay-Sachs disease prevention program in Australia: Sydney pilot study. Med J Aust 1995; 163: 298-300.

21 Spiegler GE: Genetic screening of adolescents. N Engl J Med 1997; 337: 639-640.

22 Zeesman S, Clow CL, Cartier L, Scriver CR: A private view of heterozygosity: 8 years follow-up study on carriers of the Tay-Sachs gene detected by high school screening in Montreal. Am J Med Genet 1984; 18: 769-778.

23 Lewis J, Leach J: Discussion of socio-scientific issues: the role of science knowledge. Int J Sci Educ 2006; 28: 1267-1287.

24 Lewis J, Leach J, Wood-Robinson C: All in the genes? Young people's understanding of the nature of genes. J Biol Educ 2000; 34: 74-79.

25 Lewis J, Leach J, Wood-Robinson C: Chromosomes: the missing link. Young people's understanding of mitosis, meiosis, and fertilisation. J Biol Educ 2000; 34: 189-199.

26 Lewis J, Wood-Robinson C: Genes, chromosomes, cell division and inheritance. Do students see any relationship? J Sci Educ 2000; 22: 177-195.

27 Banet E, Ayuso GE: Teaching of biological inheritance and evolution of living beings in secondary school. Int J Sci Educ 2003; 25: 373-407.
28 Pope C, Mays N: Qualitative research: reaching the parts other methods cannot reach: an introduction to qualitative methods in health and health services research. Br Med J 1995; 311: 42-45.

29 Boyatzis RE: Transforming Qualitative Information: Thematic Analysis and Code Development. California: Sage, 1998.

30 Braun V, Clarke V: Using thematic analysis in psychology. Qual Res Psychology 2006; 3: 77-101.

31 Mays N, Pope C: Qualitative research: rigour and qualitative research. BMJ 1995; 311: 109-112.

32 Keller F: Pre-operative teaching for children. Neonatal Paediatr Child Health Nurs 2001; 4: 4-9.

33 Weil J: Specific Counseling Situations and Counselees: Psychosocial Genetic Counseling. Oxford: Oxford University Press, 2000, pp 153-199.

34 Koppitz EM: Psychological Evaluation of Children's Human Figure Drawings. New York: Grune and Stratton, 1968.

35 Sarangi S, Clarke A: Constructing an account by contrast in counselling for childhood genetic testing. Soc Sci Med 2002; 54: 295-308.

36 Vygotsky LS, Rieber RW, Carton AS: The Collected Works of L.S. Vygotsky. New York: Plenum Press, 1987.

37 Rolland JS: Families, IIIness, and Disability: An Integrative Treatment Model. New York: Basic Books, 1994

38 Ayme S, Macquart- Moulin G, Julian-Reynier C, Chabal F, Giraud F: Diffusion of information about genetic risk within families. Neuromuscul Disord 1993; 3: 571-574.

39 Hamann HA, Croyle RT, Venne VL, Baty BJ, Smith KR, Botkin JR: Attitudes toward the genetic testing of children among adults in a Utah-based kindred tested for a BRCA1 mutation. Am J Med Genet 2000; 92: 25-32.

40 Fanos JH, Mackintosh MA: Never again joy without sorrow: the effect on parents of a child with ataxia-telangiectasia. Am J Med Genet 1999; 87: 413-419.

41 Canam C: Talking about cystic fibrosis within the family: what parents need to know. Issues Compr Pediatr Nurs 1986; 9: 167-178.

42 Petersen M: What are blood counts? A computer-assisted program for pediatric patients. Pediatr Nurs 1996; 22: 21-27.

43 Peters-Brown T, Fry-Mehltretter L: Genetic counselling for pregnant adolescents. $J$ Genet Couns 1996; 5: 155-168.

44 Hersh JH, Zelkp FA, Womack B et al: The role of genetic counseling in visually impaired adolescents. Kentuky Med J 1994; 92: 143-146.

45 Pilnick A: 'There are no rights and wrongs in these situations': identifying interactional difficulties in genetic counselling. Soc Health III 2002; 24: 66-88.

46 Heath C, Drew P, Heritage J: The Delivery and Reception of Diagnosis in the General Practice Consultation: Talk at Work: Interaction in Institutional Setting. Cambridge: Cambridge University Press, 1992.

47 Richards M: Genetic research, family life, and clinical practice. J Child Psychol Psychiatry 1998; 39: 291-305.

48 Nuffield Council on Bioethics: Genetic Screening Ethical Issues. London: Nuffied Council on Bioethics, 1993.

49 Procter AM, Clarke A, Harper PS: Attitudes to genetic testing in childhood in England and Wales. Am J Hum Genet 1999; 65: 2303.

50 Borry P, Goffin T, Nys H, Dierickx K: Attitudes regarding predictive genetic testing in minors: a survey of European clinical geneticists. Am J Med Genet 2008; 148: 78-83.

51 DudokdeWit AC, Tibben A, Frets PG et al: BRCA1 in the family: a case description of the psychological implications. Am J Med Genet 1997; 71: 63-71.

52 Frets PG, Niermeijer MF: Reproductive planning after genetic counselling: a perspective from the last decade. Clin Genet 1990; 38: 295-306.

53 Beeson D, Golbus M: Decision making: whether or not to have prenatal diagnosis and abortion for X-linked conditions. Am J Med Genet 1985; 20: 107-114.

54 Berry AC: Genetic counselling: a medical perspective; in: Clarke A (ed): Genetic Counselling: Practice and Principles. London: Routledge, 1994.

55 Eiser C, Patterson D, Tripp JH: IIIness experience and children's concepts of health and illness. Child Care Health Dev 1984; 10: 157-162. 